\title{
Exploring the experiences of sexual abuse survivors engaged in non-formal, arts-informed adult learning, using an arts-based research methodology
}

\section{Nicola Dickson}

To cite this article: Nicola Dickson (2021) Exploring the experiences of sexual abuse survivors engaged in non-formal, arts-informed adult learning, using an arts-based research methodology, Studies in the Education of Adults, 53:2, 238-254, DOI: 10.1080/02660830.2021.1910404

To link to this article: https://doi.org/10.1080/02660830.2021.1910404
(c) 2021 The Author(s). Published by Informa UK Limited, trading as Taylor \& Francis Group

\section{Published online: 22 Apr 2021.}

Submit your article to this journal $\pi$

\section{Џ Article views: 65}

Q View related articles $\asymp$

View Crossmark data $\nearrow$ 


\title{
Exploring the experiences of sexual abuse survivors engaged in non-formal, arts-informed adult learning, using an arts-based research methodology
}

\author{
Nicola Dickson \\ School of Education, University of Glasgow, Strathclyde, Scotland
}

\begin{abstract}
This paper explores the challenges and successes of engaging female survivors of childhood sexual abuse and sexual violence in community-based, arts-informed adult learning. The study presents the complex physical, psychological and emotional barriers to participation that were encountered during the fieldwork period. The rationale for using an arts-based research (ABR) methodology is outlined, detailing the delivery of weekly visual arts sessions and the use of women's creative outputs to enhance the qualitative research process. The critical role of the facilitator 'crafting' the women's engagement with the visual art and the research process is highlighted, emphasising the need to work reflexively and with flexibility. The paper concludes by outlining the benefits of using an ABR methodology to enhance the dissemination of the study findings and reflects on the importance of creating spaces to celebrate and platform the achievements of marginalised adult learners.
\end{abstract}

\section{KEYWORDS}

Arts-based research; nonformal education; community-based adult learning; childhood sexual abuse; marginalised women learners

\section{Introduction}

\section{Background to the study}

This paper is based on a research study that took place at a Glasgow-based charity which supports young women who are survivors of sexual abuse, sexual violence and homelessness. The service users of the charity requested an art group, held in the perceived 'safe space' of the city-centre offices. I am an adult educator and social researcher, with a passion for visual arts. I recognised this to be a unique opportunity to explore survivors' engagement in non-formal, community-based learning, and so volunteered to lead the art group. The project eventually became part of my $\mathrm{PhD}$ in Education at the University of Glasgow.

The project was framed as an exploration of arts-informed adult learning, rather than a therapeutic offering of the arts. I introduced basic visual art techniques to the

CONTACT Nicola Dickson n.dickson.1@research.gla.ac.uk University of Glasgow, 11 Eldon Street, Glasgow G3 6NH, Scotland

St. Andrew's Building, School of Education, (C) 2021 The Author(s). Published by Informa UK Limited, trading as Taylor \& Francis Group

This is an Open Access article distributed under the terms of the Creative Commons Attribution-NonCommercial-NoDerivatives License (http://creativecommons.org/licenses/by-nc-nd/4.0/), which permits non-commercial re-use, distribution, and reproduction in any medium, provided the original work is properly cited, and is not altered, transformed, or built upon in any way. 
group, using a range of $2 \mathrm{D}$ and $3 \mathrm{D}$ materials. Throughout the delivery, various challenges affected the adult learners' ability to fully participate in the project. In this paper, I begin by outlining the barriers to learning and engagement in the creative activities. I then present how the barriers to participation were identified and overcome through responsive and reflexive facilitation. In the second section, I describe how an arts-based research $(A B R)$ methodology was used to capture the participants' experience of the learning process. I argue that the ABR methodology was a good 'fit' to the research question, which sought to explore the experiences of marginalised adult learners engaged in non-formal, community-based arts sessions. I illustrate how the participatory ABR approach was effectively used to involve the adult learners in the dissemination of the research and successfully reach diverse audiences outside of academia. I conclude that this may not have been achieved if I had employed a more conventional qualitative research approach to explore the experiences of the research participants as survivors, visual artists and adult learners.

\section{A feminist, participatory, arts-based research approach}

Statistically, women are more likely than men to be survivors of childhood sexual abuse (CSA). International studies show a prevalence in the reported sexual abuse of girls and young women, with females abused at $1 \frac{1}{2}$ to 3 times the rate for males (Finkelhor 1994, Pereda et al. 2009). It is recognised that survivors of CSA can feel silenced by their perpetrators and as a result, hold an internal sense of stigma and shame (Nelson 2016). My study was shaped by the feminist research goals of enabling self-determination, emancipation, and personal and social transformation (McHugh 2014). Kara (2015) states that there is a harmony between the principles of feminist research and the participatory, creative models which employ the arts to explore experiences of marginalised groups; both can offer the disempowered greater control of the research process and empowerment as a result of their contribution. I chose to adopt what Kara (2015) terms an 'empowering creative approach'. Feminist scholars speak of the need for researchers to 'provoke us to greater awareness of voice, visibility and representation of minority, disadvantaged and oppressed people' (Douglas and Carless 2018, p. 158). By documenting women's lived experience (Ramazanoğlu and Holland 2002) a platform can be provided to privilege marginalised perspectives (Warner 2009).

Arts-based research is defined as 'the systematic use of the artistic process, the actual making of artistic expression in all of the different forms of the arts, as a primary way of understanding and examining experience by both researchers and the people they involve in their studies' (McNiff 2008, p. 29). Coemans et al. (2015) champion the arts as useful tools for social researchers trained in creative and artistic methods working in community settings. They argue that ABR approaches can 'unlock the potential of the often vulnerable populations' who might struggle to engage with more traditional research approaches (p. 34). Leavy (2015) further argues that there is a 'synergy' between arts-engagement and qualitative research, with the two creative approaches complementing one another. Janesick (2001) conceptualises both as 'crafts', which rely on the artist-researcher as the instrument who 'uses many techniques as tools to ultimately tell a story' (p. 7). In this study, I adopted multiple roles of visual artist, adult 
educator and qualitative researcher and was what Leavy (2014) terms a 'bricoleur', consciously mixing qualitative methods and artistic and educational practice, drawing on 'multiple bodies of scholarship, methods, and theories' (p. 5).

\section{Why use the terms 'vulnerable' or 'marginalised'?}

The adult learners in the study were women, aged 18-32, who self-identified as survivors of sexual abuse and sexual violence in childhood and early adolescence. All had experienced homelessness. Due to their abuse disclosure and personal circumstances, they could be considered inherently vulnerable. In research, those designated as vulnerable are often associated with powerlessness, a certain susceptibility to harm, or in need of protection. Liamputtong (2007) states that an individual is deemed vulnerable if they experience diminished autonomy due to physical, psychological or status inequalities. However, Thorneycroft (2017) reminds us that vulnerability is a problematised term, and we should recognise the corporal fragility of all humans, each with the capacity to be affected and affect others. Daley (2015) counters that even if deemed vulnerable, individuals have a right to be protected from harm and should also be able to participate in research as 'a way of being heard on matters which affect them' (p. 121). When designing the study, I considered the vulnerability of the women, in addition to their many strengths. Ultimately, the study aimed to conduct research alongside these adult learners, rather than 'on' vulnerable women. Burgess-Proctor (2015) reminds us how important this is when research is underpinned by feminist principles, as the ethics, 'emphasise embracing, rather than restricting or avoiding, research with vulnerable groups, so long as participants are neither exploited nor harmed in the process.' (their emphasis, p. 127).

It is known that disrupted schooling and largely negative encounters with formal education can create 'marginalised' adult learners (Flynn et al. 2011) and that these can lead to 'wounding learning practices' where an adult perceives themselves to be somehow incapable or inadequate as a learner (Wojecki 2007). Flannery (2002) argues that women's self-esteem can be damaged through negative experiences of early schooling, and this can have a significant impact on their identities as learners in adulthood. In addition, the trauma of sexual abuse can impact on a survivor's sense of worth in childhood and early adolescence, and result in psychological, emotional and physical issues in adult life (Kane and Bamford 2003). Studies have shown that survivors can disengage from formal, compulsory education as a result of their traumatic early experiences. For example, in Thomas and Hall (2008) study of the life trajectories of women abused in childhood, participants spoke of their negative experiences of school, with some struggling with 'distractibility, social bullying, and isolation' (p. 154). Importantly, there is limited literature exploring the experiences of female survivors of CSA as adult learners engaging in a non-formal learning environment.

\section{The research design}

\section{Recruitment}

It is recognised that CSA survivors can experience a range of psychological, emotional, social and physical difficulties, ranging in severity dependent on the needs of the 
individual (Chouliara et al. 2014). The recruitment process was complex due to the known characteristics of the service users. I asked the charity staff to act as gatekeepers and identify participants with an interest in art and adult learning, and who could feasibly participate in a six-month research study. The staff suggested a time-frame of three, six-week blocks, rather than the proposed six month period. They reasoned that some of the service users had complex and often chaotic home lives, meaning it would be difficult for them to commit to a lengthy process. I welcomed the guidance from the support staff, as they understood the needs of the women accessing the charity. Through our dialogue, other inclusion and exclusion criteria were developed. We agreed that psychological stability was important, meaning women that were at risk to themselves or others could not be selected. This included women that the staff termed 'in crisis', 'heavily' under the influence of drink or drugs, and those who were violent or 'actively suicidal'. The ethical considerations for working with this group were complex, and it was important to reflect on my own psychological wellbeing when working with potentially emotionally vulnerable participants. Before fieldwork began, I identified and approached three individuals who routinely worked with survivors. They agreed to mentor me throughout the length of the project. This was useful, as I faced some challenging behavioural issues during fieldwork.

In total, nine women were identified to participate in the art making, learning and research process. All were white and Scottish. They described themselves as coming from working-class backgrounds. Four were 'short-term' service users who had been with the charity for less than two years and were in temporary accommodation. Five were longterm users had accessed the charity between 5 and 13 years. All the names used in this research are pseudonyms. These were selected by the adult learners during the fieldwork period. During an art session, the women were asked what they would like to be called in the research. As a group, they searched a UK website which listed 'strong women' from history and fiction and discussed what they would like to be called. This was an important step in the participatory, feminist research process. Burgess-Proctor (2015) reminds us that assigning pseudonyms to participants after research is important, in order to meet the requirements for identity protection, yet 'asking participants to select their own pseudonyms accomplishes the same goal but does so with an explicit empowerment for research participants' (p. 130). In the following section I present my practice, which gives an overview of my teaching approach and the research tools I used to explore the experiences of the adult learners and capture the perceptions of the charity staff and stakeholder.

\section{The practice}

A weekly, two-hour visual art class began in May 2018. I introduced different forms of artistic expression and techniques over the weeks in various media, including paint, pastel, pen and pencil, wire, plaster and modelling clay. I designed and delivered the teaching, providing the materials and practical exercises, and giving examples of finished artwork. Permission was given to photograph the adult learners' artwork during the sessions on my smartphone. Following each session I wrote an account of my observations, which formed a reflexive journal. Contrary to the expectations of the 
support staff, I was asked by the adult learners to continue the art classes past the 18week timeframe. The project lasted over six months, until October 2018.

Towards the end of the fieldwork period, the adult learners were invited to participate in in-depth interviews to reflect on the experience of the art group. I created a digital media presentation for each participant, based on the photographs taken during the sessions. This was uploaded onto a Tablet and offered at the beginning of the in-depth interview. Each participant was encouraged to lead the discussion and 'swipe through' the slides, commenting on the sessions and describing how they felt at different points in the study. As a feminist researcher, I hoped that my method of interviewing would offer the participants a feeling of 'personal involvement and satisfaction' (Cotterill 1992, p. 595). My approach was designed to counter the power imbalances and shifting authority of the in-depth interview (Oakley 1981, Hesse-Biber 2007, DeVault and Gross 2012): by giving the participant the device, they had greater control of the direction of the conversation. A semi-structured interview schedule was developed as a guide, but I was careful to listen, watch and work respectfully (Stanley and Wise 1993), always attentive to the flow of the conversation. Where appropriate, the participants were prompted to focus on an image and speak about their feelings about a session. Arguably, the use of the artworks introduced reflexivity into the research design (Weber 2008): the visual prop acted as a useful tool for many of the adult learners who, due to multiple factors, had forgotten some aspects of their involvement with the study.

Following the adult learner interviews, I asked five staff members and the former Chair of the Board of Directors to participate in additional interviews, as I wanted to explore their perceptions of the project. For these I prepared a more generalised presentation, outlining the techniques and creative outputs from each of the collective sessions (an example of a slide used in the staff and stakeholder interviews is shown in Figure 1).

\section{Session 4 - Oil pastel and cartridge paper}
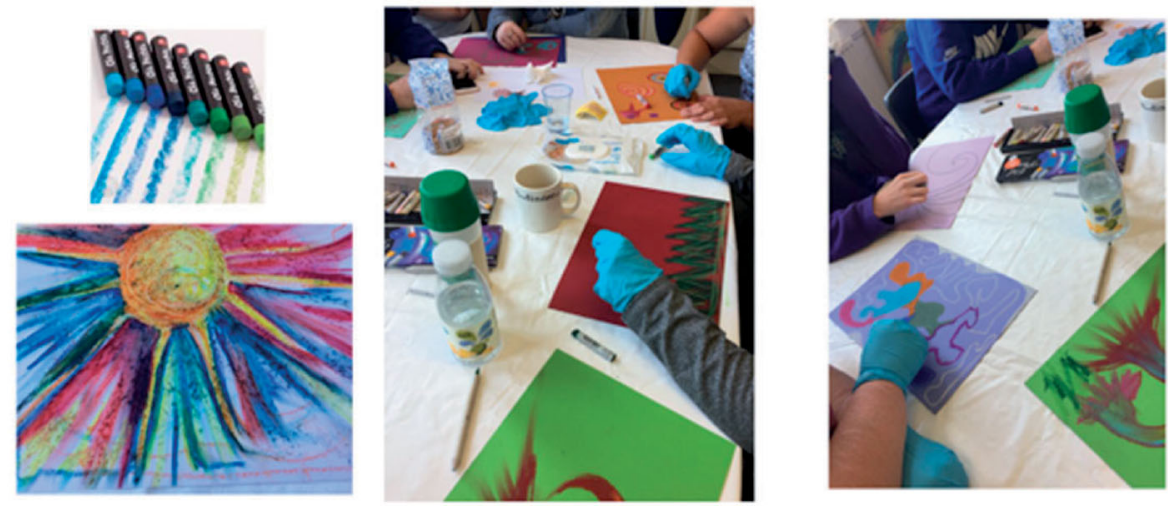

Figure 1. Slide showing group session. 


\section{Data analysis}

I transcribed the interviews, focussing on the words spoken but also the intonation, pitch, amplitude and pace of talk. Hammersley (2012) highlights how the transcription of speech is an important component to the analysis process. I noticed when listening to the audio recordings how the adult learners used non-word elements when reacting to the slides, making noises such as saying 'uhuh', laughing or using other expressive sounds. These were important to capture when coding the data. Both the interview transcripts and my own reflexive journal entries were analysed thematically, identifying patterns and using these to summarise and organise the data (Braun and Clarke 2006). I reflected on my research questions and used the qualitative data analysis software, NVivo, to organise, code and interrogate the data. I repeatedly revisited the individualised presentations when reviewing the coded transcripts to enhance my understanding of the words spoken in interview. If a specific image elicited a particularly strong emotional response for an individual, I compared this to how others found the art making experience.

\section{Findings and discussion}

Complex barriers to engagement, including situational and dispositional barriers to learning, were encountered during the fieldwork period (Cross 1981). Situational barriers arose from life situations, such as moving from temporary accommodation to rental properties or maintaining difficult relationships with friends and family members. Dispositional barriers included ingrained negative or ambivalent attitudes towards learning and education. In addition to the internal psychological conflicts affecting engagement with non-formal learning opportunities, the challenges to group work were multiple and complex. Many of the women struggled to be in the space and perform as artists, adult learners and research participants. Some coped with the physical effects of strong medication, others battled chronic physical pain. All were scarred with self-harm marks on their arms and bodies. During the art sessions, the participants discussed how these issues impacted on their lives. They spoke of sleep deprivation, anxiety and depression, fear and paranoia (which made travel extremely challenging). Drug-use and alcohol dependency affected their time keeping and ability to learn. In the discussion section, I present the obstacles to participation in non-formal adult education based on the women's dispositional barriers to learning, and how in response to these challenges I modified my style of delivery and reflected on my learning outcomes expectations.

There were key benefits of using an ABR approach to explore the experiences of the survivors as adult learners. Leavy (2015) argues that the methodological tools of the ABR approach allow for enhanced data generation, analysis, interpretation and representation. For Leavy (2018), the strength of the ABR approach is the ability to represent research 'differently and to reach broader audiences.' She argues that, 'the research carries the potential to jar people to seeing and/or thinking differently, feeling more deeply, learning something new, or building an understanding across similarities and differences' (p. 9). In this study, the visual art created in the adult learning sessions and the reflections from the in-depth interviews were combined to create an exhibition of 
the women's artwork and words. The collection was showcased to both academic and community audiences. The ABR approach successfully reached diverse audiences, but also provided an opportunity to celebrate the participants, platform their contributions to the research and promote the positive transformations linked to involvement in non-formal adult education.

\section{Barriers and enablers to arts-informed adult learning}

\section{Barriers to participation in learning and art making}

In the in-depth interviews, the adult learners reflected on their experiences of formal education. All reported varying levels of disrupted schooling. This was due to a variety of factors, including absenteeism, chaotic homelives and ill health. Some spoke of feelings of shame, fear and frustration when at school. For many of the adult learners, literacy issues compounded their feelings of inadequacy. Two participants indicated that they had been a disruptive presence in the classroom. Interestingly, both stated that they were disruptive in all classes but art, as the following quote illustrates:

I didn't read or write until I was 17 , so in school I loved doing my art. To be fair I was a wee $\mathrm{a}^{* * *}$ hole at the time, just kicking off ... art was the only class I was really allowed in. I wasn't destructive in art. I was a bit of a wee $a^{* * *}$ hole, but not in art. (Cleo, age 22, short-term service user).

Engaging in art and developing creative skills was identified as a positive experience by many of the adult learners in the study. It was suggested by the charity support staff that visual art was a useful tool to communicate and understand their responses to trauma, and was encouraged as part of the women's pastoral care. For the majority of the adult learners in my study, art making was considered to be a largely enjoyable activity. However, many spoke of the detrimental impact of being graded or assessed on their artistic merit when at secondary school. It was suggested that the introduction of a fixed curriculum and assessment compounded their feelings of frustration and worthlessness and distracted from what was once an enjoyable creative outlet. Field (2009) warns that anxiety and stress can be associated with learning, especially if it involves assessment which can hold the threat of failure. In the interview, one participant spoke of the discomfort she experienced in school when a teacher graded her artworks:

I've hated drawing since school. Hated it, with a passion. They made you draw things and then they graded you on it. I was like so you're making me draw things I don't want to draw, with materials I don't want to use, and then you're going to tell me it's $\mathrm{sh}^{* *}$ e. I'm like, why are you doing this to me? (Liz, age 30, long-term service user).

Survivors of CSA are known to struggle with deep-rooted feelings of shame, low self-esteem and trust issues (Robst 2010). The impact of poor self-esteem and lowworth did affect the adult learner's perceived abilities and expectations of success. During the fieldwork, I introduced art techniques which were attempted by the group members but often rejected. Their efforts were deemed 'junk' and 'for the bin'. In the in-depth interviews, I showed staff and stakeholders artworks which had been 
destroyed or left unfinished. These destructive acts were linked to the adult learners' poor self-worth, as the stakeholder of the charity described in the interview:

These young women could have been told 'you're thick' and 'you're crap at everything' and their self-worth and self-advocacy could be very, very poor. You have to begin by understanding that before you try to engage. (Margaret, charity stakeholder).

The art making process can be considered to be a mechanism for personal empowerment and emotional release. Interestingly, for many of the adult learners in my study, art making was rarely referred to as an empowering act. For most, the aesthetics of the artworks impacted on the perceived success or failure of the women as adult learners. For many, the need to 'get it right' was all encompassing, to the extent that it affected their ability to work with the materials. In the interviews, the support staff linked the need to control the aesthetics of their creative outputs to the women's abuse histories and resulting low self-esteem:

There is a real kind of conflict of accepting themselves and seeing themselves as good enough, and that's been played out and externalised in the art they're doing. (Aggie, pastoral support staff).

The detrimental drive for perfectionism was recognised by the adult learners. They struggled to engage with the art making because of their self-consciousness and overriding need for control. In the interview, when reflecting on the imagery from the sessions, many vocalised the frustration they felt when trying to achieve an effect. One participant revealed how uncomfortable she felt during the session when her efforts were praised:

I've got too high standards, impossible standards really. I'm learning to deal with that... I get really uncomfortable. I get a feeling in my stomach. See when you come up and say, 'Oh that's good' and I don't think it's good, I get that 'want to go out of the door feeling'. (Vicky, age 31, long-term service user).

Rather than being an empowering process, many of the participants highlighted the feelings of anger and irritation when attempting new techniques or artistic approaches. One example of this came from the model making session (see Figure 2) where an adult learner became deeply frustrated. During the session, she threw her piece across the room, swore and left the building. In the interview, she looked at the photograph of her broken artwork and spoke about the external factors which affected her that day. She said she had lost her temper, which was upsetting, but she felt better for the release of emotions:

I struggled that day just to come in. I nearly didn't come in. But I'd been enjoying it so much that I thought it would be good for me to come in. And it kinda was actually. I left feeling a lot better than when I arrived. But it's hard when you've got other stuff going on to maintain the emotions. (Liz, age 30, long-term service user).

The model making activity was particularly challenging for a number of participants. In the interview, another participant spoke of how she travelled home 'shaking' with anger following the session. Her inability to manipulate the modelling clay and make it look 'right' left her feeling anger and disappointment. Her frustration was so great she had to self-sooth with alcohol following the session:

It got me that angry, I got outside and I was shaking! All to do with the art (laughs). Even when I got back home, I was still shaking. I got back and called into my 


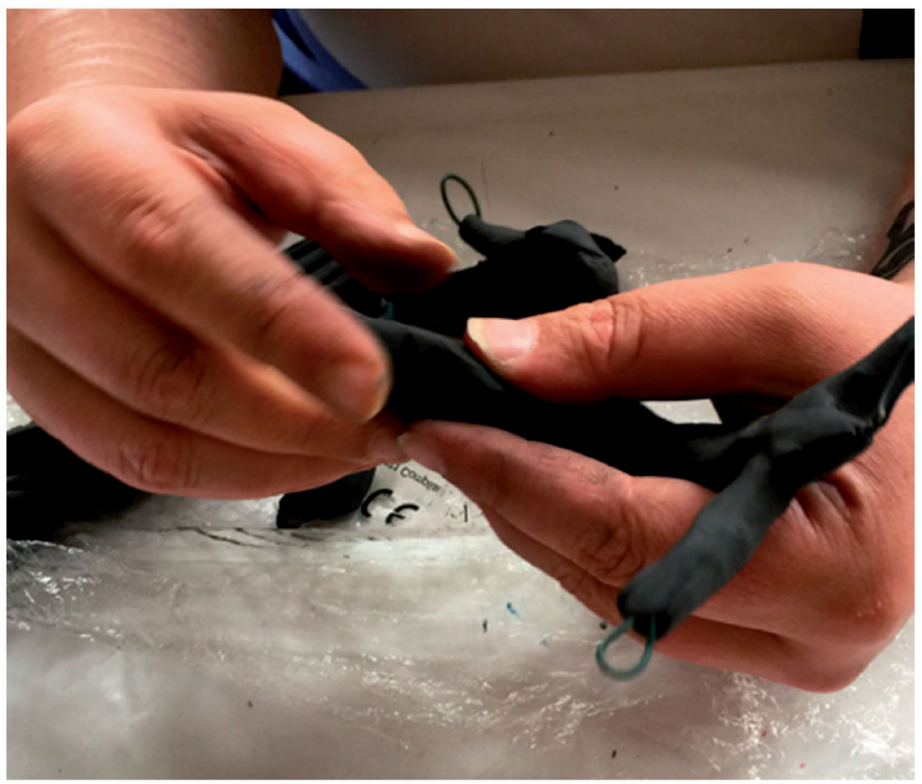

Figure 2. Model making session.

neighbours (and) she's like, 'You're shaking' and I said, 'I know wait till I open and drink this can of cider and the shaking will stop' and it did, it stopped. (Vicky, age 31, long-term service user).

\section{Enablers to participation}

Taylor (2008) argues that an adult educator can face many challenges when attempting to promote learner involvement in the non-formal educational experience. He highlights the educator's role in fostering a positive and supportive environment, by continually assessing learner need, recognising interests and establishing rapport. As the educator, researcher and artist of this study, I recognised how important it was to be 'methodologically reflective' (Coemans and Hannes 2017) and consider how my different roles might impact on the engagement of the adult learners. I elected to keep a reflexive journal to reflect on my experiences as an artist-facilitator. Janesick (2014) states that in qualitative research, the reflexive journal is an 'effective tool for understanding the processes of research more fully, as well as the experiences, mindsets, biases, and emotional states of the researcher' (p. 306). Warner (2009) argues that tools that encourage reflexivity 'force the researcher to take greater responsibility for her actions through the persistent demand to reflect on their effects' (p. 77). Oleson (2018) advises that 'reflexivity demands steady, uncomfortable assessment about the interpersonal and interstitial knowledge-producing dynamics of qualitative research' (p. 160). The critical reflexive journal allowed me to articulate and analyse the difficulties faced when trying to engage resistant learners in art techniques. This insight led me to modify my facilitation style; I changed the delivery of the sessions, slowed the pace and provided more opportunities for self-directed learning. By documenting and reflecting on the group dynamics, including body language, perceived interest and uptake of the 
activities, I was able to re-assess and repackage my approach. I recognised that my initial expectations of the group were unrealistic and unattainable. I had designed a curriculum of art activities, with specific learning outcomes and outputs, but had not considered the complex barriers to learning and engagement. Many in the group had 'fragile identities' as learners (Tett and Maclachlan 2007), as artists and as contributors to a participatory research project. I noted in my reflexive diary following the fourth session:

'I changed the pace and the difficulty level of the art activities today. I was a bit shocked and disappointed last week when the group showed such discomfort with my planned warm-ups and session plan. I thought it would be fun and non-threatening! It was not.' (Reflective journal entry).

Through modifying my facilitation, the group dynamics changed and the adult learners became visibly more relaxed in the space. The previously rigid and structured activities were revised, and instead presented as an opportunity to 'play' with art materials and learn new techniques for artistic expression. My approach was influenced by feminist popular educators Manicom and Walters (2012), who speak of the need to provide 'delicate spaces' for women to learn and 'create a sense of community and levity' (p. 11). The environment was cultivated to be supportive, nurturing and where possible, fun. I reiterated that there was no grading and no negative comments would be given on the aesthetic quality of the artworks. Those who did not want to follow the session plan were given the opportunity to explore other materials or simply observe. One respondent stated that the sessions felt 'like school but fun' because 'we all knew that we had something to do but like... It didn't feel pressured.' (Cleo, age 22, short-term service user).

Staff commented that my flexible and friendly delivery was critical to the project success. They stated that by giving the freedom to engage with the art materials and approaches, the adult learners felt greater ownership of the process. In the interview, one staff member indicated that recognising autonomy and control was essential when working with survivors of sexual abuse:

They have control of what they do within the group because that's one of the things that's been so difficult for them, they've had their control taken away from them. So I think that's why they like the group, because there isn't pressure. And I think that's why they are attending. (Aggie, pastoral support worker).

In the in-depth interviews, the adult learners were asked how they would have felt if they had been forced to take part in a planned art activity with key learning outcomes. Most stated that they would have done it, but probably would not return to the group. One warned how detrimental this approach might have been to her engagement with the process:

I go a little bit in $\mathrm{p}^{* * *} \mathrm{y}$ when people try to make me do stuff. So I'll be like, I wouldn't talk to you like... Just (be) a bit raging. Not like violent or anything but I'd freeze you out. (Luna, age 19, short-term service user).

\section{The exhibition of the artwork and celebration of adult learners}

In the final months of fieldwork, the adult learners' attendance became less consistent. Many were going through periods of transition, including new homes, jobs and relationships, which formed situational barriers and impacted on their ability to join the 
weekly group. Therefore, I asked the charity staff to contact the adult learners and invite them to help curate an exhibition of their artworks. It was proposed that these would be displayed to staff, stakeholders and service users at the charity's Annual General Meeting (AGM) in October 2018. Following this announcement, attendance increased and individuals came in outside of the taught sessions to complete their artworks. In interview, the adult learners were asked how they felt about producing visual art for an exhibition. For all, the pride was palpable. One respondent reflected:

I feel quite big-headed (laughs). I feel quite proud. I feel quite proud it's being put on display. (Cleo, age 22, short-term service user).

Another recognised how displaying her artwork and contributing to an exhibition demonstrated positive steps forward in the development of her self-esteem. She stated:

I wouldn't put anything that I've done up on my wall, I've never done anything like that before, so this is like a new... This is me so this is accepting that my good is good enough, or trying to! (laughs). (Vicky, age 31, long-term service user).

Tuckett (2018) identifies how important it is to provide a 'space for adults to celebrate the delights, the challenges and joys of learning' (p. 13) through making adult learning visible and vocal. At the AGM, the adult learners were celebrated. A booklet was produced by the charity, with images of the artwork and narratives about the adult learners' experiences (See Figure 3). Eight of the nine adult learners attended the exhibition at the AGM. Four volunteered to introduce the artworks and speak about their involvement in the study. They presented for over 30 minutes to a crowded auditorium. I had not expected this performative contribution and it was wonderful to observe. The



Figure 3. Booklet produced by the adult learners. 
exhibition was considered a great success by both the adult learners and audience members. In the interview, one stakeholder reflected on the importance of celebrating the women's achievements:

These women have been hiding from the world with shame, with guilt with anger, rage, deep distress. And here they are (in a) public bloody space (saying), 'Here I am!', I mean what a powerful thing! (Margaret, charity stakeholder).

\section{Dissemination of ABR findings}

Eisner (2008) contends that an arts-researcher must recognise and understand the 'distinctive potential' of the chosen art form and know how 'to treat a material so that it becomes a medium of expression' (p. 9). As an ABR project, I knew it was important to use the visual products of the learning and research in the dissemination of the research findings, to provide an opportunity for 'people to consume or experience ABR' (Leavy 2018, p. 10). Following the AGM exhibition, I sought other opportunities to share the research findings and create critical awareness of the role of non-formal arts-informed education for marginalised adult learners. In 2019, I was invited to exhibit my research findings at the Scottish Graduate School of Arts and Humanities (SGSAH) 'research showcase' to celebrate 5 years of creativity and innovation in doctoral research. As the artworks had been returned to the charity, I chose to create 10, double-sided A1 poster boards, featuring photographs of the women's art (on one side) and process images and quotes from the in-depth interviews on the other (see Figure 4). When using ABR methods as a dissemination tool, ethical considerations and the power of the researcher should be taken
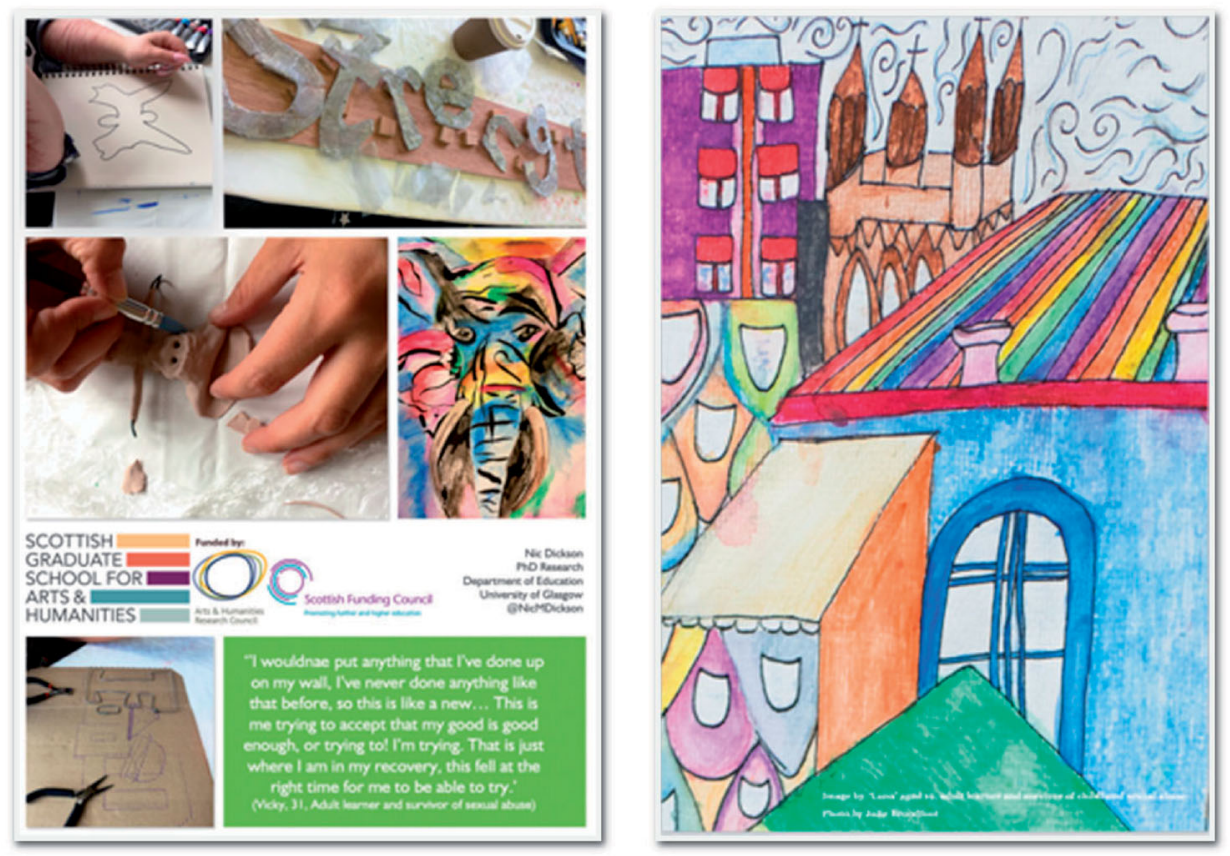

Figure 4. Double-sided poster boards created for the research showcase. 
into account (Coemans and Hannes 2017). Cognisant of my potentially powerful position, I approached the charity and invited the adult learners to help shape the representation of the research findings. My intention was for all stages of the research to be as participatory and empowering as possible. Four of the nine adult learners agreed to attend an additional session and look at the images and a selection of quotes from the in-depth interviews. Unfortunately the process did not result in full and equal collaboration. The small group struggled to select images and declined to read or listen to the quotes, which they deemed 'too embarrassing' to hear. They were not willing or able to make decisions on the content on the boards, telling me to choose the images and words. Afterwards, I spoke to the support staff about this reticence. They reasoned that the show of indifference could be due to confidence issues or other priorities in the women's lives. I had hoped that the women would share my passion and enthusiasm for the research process, but I now recognise how deeply invested I was in the work as an artist-practitioner. Aldridge (2015) reminds us that when engaging vulnerable groups in participatory research, the instigator must ensure the 'research relationships are based on mutuality, understanding and trust and, depending on the nature and extent of the participatory principles and objectives (what is achievable and realistic in research terms), that the voices of participants are prioritised over those of academic researchers' (p. 158). On reflection, it was not realistic to task the research participants with selecting the quotes or choosing images to use on the poster boards. It was, however, possible to ensure the women were consulted, given the opportunity to shape the content and it was shown that their 'voices' were valued.

The boards were created and exhibited at the research showcase and were well received by academic audiences. Following the success for the project, I went on to independently create a short film based on my research for the University of Glasgow's 'Impact in 60 seconds' competition. Again, the service users were invited to give feedback on the film, but this was not received before submission. In September 2019 the film was shown at the Glasgow Film Theatre, where it received the first prize (see Figure 5).

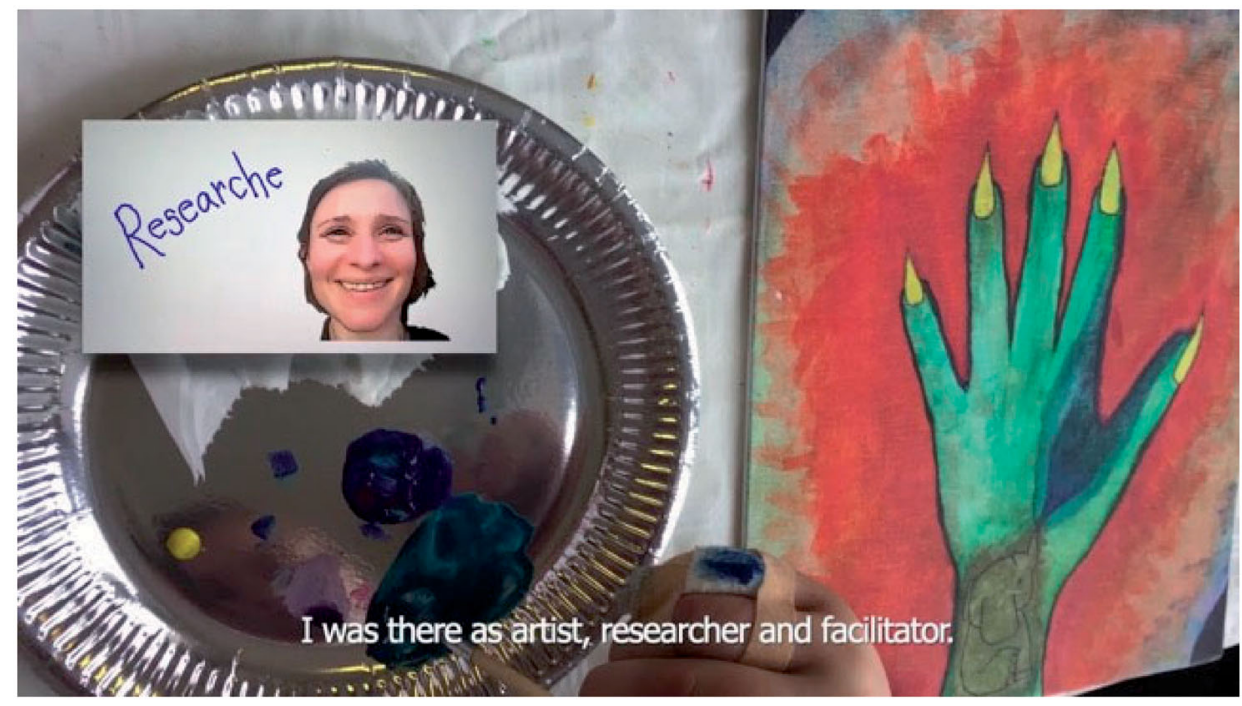

Figure 5. Short award-winning video. 
Cole and Knowles (2008) remind us that the arts-informed research approach should 'enhance understanding of the human condition through alternative (to conventional) processes and representational forms of inquiry, and to reach multiple audiences by making scholarship more accessible' (p. 59). Inspired by this ethos, I offered the poster boards, short video and booklets for display at the University of Glasgow. The collection was exhibited from November 2019 to January 2020, mostly to academic audiences. In Spring 2020, the exhibition was taken to the Glasgow Women's Library (GWL), an iconic building in the heart of the city (https://womenslibrary.org.uk/event/ say-artists). Those involved in the research were invited to visit the venue and help set up the exhibition. This was successful, with three staff members and two adult learners curating the space. Before opening to the public, a private launch event was organised for the service users, staff and stakeholders of the charity to come and see the work on the walls. Six of the nine adult learners attended the exclusive event. Three of the adult learners did not attend the final exhibition at the GWL; two no longer had a connection with the charity, a third was invited but did not want to be publicly recognised as a service user of a charity for survivors of sexual abuse.

The responses of the women who attended the private launch event were captured in a comment book. There was a marked joy amongst all the audience members, but particularly for the adult learners who had been involved in the ABR process. Figure 6 highlights the elation, positive self-regard and pride that stemmed from being identified as an artist, whose work has been selected for exhibition. It is joyful and celebratory, alluding to a sense of place and identity, and was gratifying to read. Clover (2012) proposes that, 'if artistic identity means coming to see oneself both privately and publicly as an artist, how is it done? One way is to learn to be an "artist" and show one's art publicly' (p. 201). By making the women's artwork visible, the participants were 'transformed as subjects of their experiences' (Ramdeholl and Jones 2015, p. 268) and enabled to revise their fragile learner identities. They became more than survivors, they were celebrated visual artists who in Cleo's words, could be recognised as 'proper' people in a place of cultural significance.

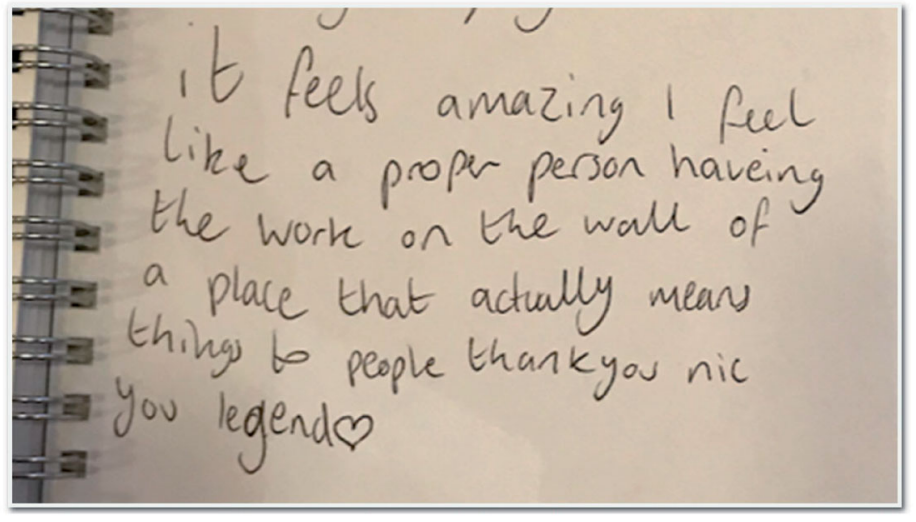

Figure 6. Extract from comment book in the 'SAY Artist' exhibition at the Glasgow Women's Library by adult learner, research participant and artist 'Cleo' (February 2020). 


\section{Conclusion}

This paper gives a critical insight into the successes and challenges of using an ABR approach to explore the experiences of survivors engaged in arts-informed, adult learning. The study found that the abuse histories of the adult learners profoundly impacted on their ability to engage with non-formal learning. Creating art was difficult for those that were impaired by their own perfectionism and need for control. By working reflexively and ensuring responsive facilitation, a safe space was created for the participants to engage with the creative process.

Low esteem and confidence issues, linked to the trauma endured in childhood and early adolescence, affected the women's ability to contribute to all aspects of the ABR process. However, the ABR approach was deemed successful, as it generated data beyond the scope of typical qualitative research interviews or participant observation processes (Chilton and Leavy 2014). Arguably, the ABR methodology enhanced both the data collection process and the dissemination of the research findings. By exhibiting the artwork and adult learners' words in different media (video and print) in three different venues over a three-year period, the women in this study had their identities as survivors, artists and adult learners celebrated and their voices 'heard'.

\section{Disclosure statement}

No potential conflict of interest was reported by the author(s).

\section{ORCID}

Nicola Dickson (iD http://orcid.org/0000-0003-0084-605X

\section{References}

Aldridge, J., 2015. Participatory research: working with vulnerable groups in research and practice. Bristol: Policy Press.

Braun, V., and Clarke, V., 2006. Using thematic analysis in psychology. Qualitative research in psychology, 3 (2), 77-101.

Burgess-Proctor, A., 2015. Methodological and ethical issues in feminist research with abused women: reflections on participants' vulnerability and empowerment. Women's studies international forum, 48, 124-134.

Chilton, G., and Leavy, P., 2014. Arts-based research practice: merging social research and the creative arts. In: P. Leavy's, Ed. The Oxford handbook of qualitative research. USA: Oxford University Press, 403-442.

Chouliara, Z., Karatzias, T., and Gullone, A., 2014. Recovering from childhood sexual abuse: a theoretical framework for practice and research. Journal of psychiatric and mental health nursing, 21 (1), 69-78.

Clover, D., 2012. Feminist artists and popular education: the creative turn. In: L. Manicom and S. Walters, Eds. Feminist popular education in transnational debates: building pedagogies of possibility. New York: Springer, 193-208.

Coemans, S., and Hannes, K., 2017. Researchers under the spell of the arts: two decades of using arts-based methods in community-based inquiry with vulnerable populations. Educational research review, 22, 34-49. 
Coemans, S., et al., 2015. The use of arts-based methods in community-based research with vulnerable populations: protocol for a scoping review. International journal of educational research, 71, 33-39.

Cole, A. L., and Knowles, J. G., 2008. Arts-informed research. In: J. G. Knowles and A. L. Cole's, eds. Handbook of the arts in qualitative research: perspectives, methodologies, examples, and issues. Los Angeles: Sage Publications, 55-70.

Cotterill, P., 1992. Interviewing women: issues of friendship, vulnerability, and power. Women's studies international forum, 15 (5-6), 593-606.

Cross, K. P., 1981. Adults as learners: increasing participation and facilitating learning. San Francisco: Jossey-Bass.

Daley, K., 2015. The wrongs of protection: balancing protection and participation in research with marginalised young people. Journal of sociology, 51 (2), 121-138.

DeVault, M., and Gross, G., 2012. Feminist qualitative interviewing: experience, talk, and knowledge. In: S. N. Hesse-Biber, ed. Handbook of feminist research: theory and praxis. Chapter 11. Thousand Oaks: SAGE Publications, 206-236.

Douglas, K., and Carless, D., 2018. Engaging with arts-based research: a story in three parts. Qualitative research in psychology, 15 (2-3), 156-172.

Eisner, E., 2008. Art and knowledge. In: J. G. Knowles and A. L. Cole, eds. Handbook of the arts in qualitative research: perspectives, methodologies, examples and issues. Chapter 1. Los Angeles: SAGE publications, 3-12.

Field, J., 2009. Good for your soul? Adult learning and mental well-being. International journal of lifelong education, 28 (2), 175-191.

Finkelhor, D., 1994. The international epidemiology of child sexual abuse. Child abuse \& neglect, 18 (5), 409-417.

Flannery, D. D., 2002. Identity and self-esteem. In: E. Hayes and D. D. Flannery, eds. Women as learners, the significance of gender in adult learning. San Francisco: Jossey-Bass Publishers, 53-78.

Flynn, S., et al., 2011. Barriers to education for the marginalized adult learner. Alberta journal of educational research, $57,43-58$.

Glasgow Women's Library. (2020). 'SAY artists' exhibition. Available from: https://womenslibrary.org.uk/event/say-artists/ [Accessed 21 August 2020].

Hammersley, M., 2012. Transcription of speech. In: S. Delamont, ed. Handbook of qualitative research in education, (Chapter 32). New York: Edward Elgar Publishing, 439-445.

Hesse-Biber, S. N., 2007. Putting it together: feminist research practice. In: S. N. Hesse-Biber and P. Leavy, eds. Feminist research practice: a primer. California: Sage Publications, 329-350.

Janesick, V.J., 2001. Intuition and creativity: a pas de deux for qualitative researchers. Qualitative inquiry, 7 (5), 531-540.

Janesick, V. J., 2014. Oral history interviewing: issues and possibilities. In: P. Leavy (Ed.). The Oxford handbook of qualitative research. USA: Oxford University Press, 300-314.

Kara, H., 2015. Creative research methods in the social sciences: a practical guide. Bristol: Policy Press.

Kane, K., and Bamford, D., 2003. A review of education/support groups for adult survivors of child sexual abuse: a qualitative analysis. Practice, 15 (4), 7-20.

Leavy, P., 2014. The Oxford handbook of qualitative research. New York: Oxford University Press.

Leavy, P., 2015. Method meets art: arts-based research practice. New York: Guilford Publications.

Leavy, P., 2018. Handbook of arts-based research. New York: Guilford Publications.

Liamputtong, P., 2007. Researching the vulnerable: a guide to sensitive research methods. London: Sage.

Manicom, L., and Walters, S., 2012. Feminist popular education in transnational debates: building pedagogies of possibility. New York: Springer. 
McHugh, M. C., 2014. Feminist qualitative research: toward transformation of science and society. In: P. Leavy, Ed. The Oxford handbook of qualitative research. Oxford: Oxford University Press, 137-164.

McNiff, S., 2008. Arts-based research. In: J. G. Knowles and A. L. Cole, eds. Handbook of arts in qualitative research: perspectives, methodologies, examples, and issues (Chapter 3). California: Sage Publications, 29-40.

Nelson, S., 2016. Tackling child sexual abuse: radical approaches to prevention, protection and support. Bristol: Policy Press.

Oakley, A., 1981. Interviewing women: a contradiction in terms. Doing feminist research, 30 (6), 1.

Oleson, V., 2018. Feminist qualitative research in the millennium's first decade: developments, challenges, prospects. In: N. K. Denzin and Y. S. Lincoln, eds. The Sage handbook of qualitative research (5th ed.). Thousand Oaks: Sage, 151-175.

Pereda, N., et al., 2009. The international epidemiology of child sexual abuse: a continuation of Finkelhor (1994). Child abuse \& neglect, 33 (6), 331-342.

Ramazanoğlu, C., and Holland, J., 2002. Choices and decisions: doing a feminist research project. In: Feminist methodology: challenges and choices. Thousand Oaks: SAGE, 145-164.

Ramdeholl, D., and Jones, J., 2015. Weaving quilts and building community: study circles to reimagine women's spaces/places in adult literacy. In: Annual conference proceedings: proceedings of the 2015 annual conference of CASAE/ACEEA. Quebec, Canada: University of Montreal, 266-270.

Robst, J., 2010. Childhood sexual victimization, educational attainment, and the returns to schooling. Education economics, 18 (4), 407-421.

Stanley, L., and Wise, S., 1993. Breaking out again: feminist ontology and epistemology. London: Routledge.

Taylor, E.W., 2008. Teaching and emotions in a nonformal educational setting. New directions for adult and continuing education, 2008 (120), 79-87.

Tett, L., and Maclachlan, K., 2007. Adult literacy and numeracy, social capital, learner identities and self-confidence. Studies in the education of adults, 39 (2), 150-167.

Thomas, S.P., and Hall, J.M., 2008. Life trajectories of female child abuse survivors thriving in adulthood. Qualitative health research, 18 (2), 149-166.

Thorneycroft, R., 2017. Problematising and reconceptualising 'vulnerability' in the context of disablist violence. In: N. L. Asquith, I. Bartkowiak-Theron, and K. A. Roberts, eds. Policing encounters with vulnerability. London: Palgrave Macmillan, 27-45.

Tuckett, A., 2018. Adult education for a change: advocacy, learning festivals, migration, and the pursuit of equity and social justice. Journal of adult and continuing education, 2018, 147797141879665.

Warner, S., 2009. Understanding the effects of child sexual abuse: feminist revolutions in theory, research and practice. New York: Routledge.

Weber, S., 2008. Visual images in research. In: J. G. Knowles and A. L. Cole's, eds. Handbook of the arts in qualitive research: perspectives, methodologies, examples and issues. California: Sage Publications.

Wojecki, A., 2007. What's identity got to do with it, anyway?' Constructing adult learner identities in the workplace. Studies in the education of adults, 39 (2), 168-182. 